\title{
Kinetics and Mechanism of Oxidation of Vanillin by Chromium(VI) in Sulfuric Acid Medium
}

\author{
Ahmed Fawzy ${ }^{1,2 *}$, Ishaq Zaafarany ${ }^{1}$, Khalid Khairou ${ }^{1}$, Ismail Althagafi ${ }^{1}$ and Jabir Alfahemi ${ }^{1}$ \\ ${ }^{1}$ Chemistry Department, Faculty of Applied Science, Umm Al-Qura University, 21955 Makkah, Saudi Arabia \\ ${ }^{2}$ Chemistry Department, Faculty of Science, Assiut University, 71516 Assiut, Egypt
}

\begin{abstract}
The kinetics of oxidation of vanillin (VAN) by chromium(VI) in sulfuric acid medium was studied by a spectrophotometric technique. The reaction exhibited a first order dependence with respect to $[\mathrm{Cr}(\mathrm{VI})]$ and fractionalfirst orders with respect to [VAN] and $\left[\mathrm{H}^{+}\right]$. Varying ionic strength or dielectric constant of the reaction medium had no significant effect on the oxidation rate. The proposed mechanism includes an intermediate complex formation between vanillin and chromium( $\mathrm{VI}$ ) before the rate-determining step. The final oxidation product of vanillin was identified by both spectral and chemical analysis as vanillic acid. The suitable rate law has been deduced. The reaction constants included in the various steps of the suggested mechanism have been evaluated. The activation parameters of the rate constant of the rate-determining step of the mechanism and the thermodynamic quantities of the equilibrium constant have been evaluated and discussed.
\end{abstract}

Keywords: Vanillin; Chromium(VI); Oxidation; Kinetics; Mechanism

\section{Introduction}

Vanillin is a phenolic aldehyde, which is an organic compound including aldehyde, hydroxyl and ether. It is the primary component of the extract of the vanilla bean. Vanillin is a significant flavoring reagent in the industry of food and is widely used in the production of drugs. It has been also used as a chemical intermediate in the preparation of pharmaceuticals and other fine chemicals. Furthermore, it is used in the synthesis of perfume and as a catalyst in various polymerization reactions. When the hydroxyl group in vanillin molecule is protected, vanillin is oxidized to vanillic acid [1]. Kinetics of oxidation of vanillin has been studied previously in alkaline solutions by different reagents, as hexacyanoferrate(III) [2], diperiodatoargentate(III) [3], bismuth(V) [4], diperiodatonickelate(IV) [5] and periodate catalyzed by ruthenium(III) [6], and in acid media by cerium(IV) [7]

Oxidation reactions are very important in nature and in organic synthesis. Among the most important oxidants is chromium(VI) which may play a significant role in the chemistry of vanillin in the environment due to the mutagenic and carcinogenic activity of chromium. Chromium exists in both trivalent, $\mathrm{Cr}(\mathrm{III})$, and hexavalent, $\mathrm{Cr}(\mathrm{VI})$, species in aqueous solutions and the two oxidation states are identified by various physical/chemical behavior and toxicity. Chromium(VI) compounds are very dangerous for biological systems, but those of chromium(III) are relatively non-toxic [8]. Chromium(VI) is employed for oxidation of organic compounds and it is reduced to lower oxidation states [9]. The chemistry of $\mathrm{Cr}(\mathrm{V})$ and $\mathrm{Cr}(\mathrm{IV})$ as intermediate species which may be formed during reduction of chromium(VI) were attracted many researchers because of their involvement in the mechanism of $\mathrm{Cr}$-induced cancers [10].

A literature survey revealed that various literature are available on the kinetics of chromium(VI) oxidations of different inorganic [11-15] and organic [16-24] substrates, whereas there is no available reports on the oxidation of the vanillin by this oxidant. Owing to the above arguments, the title reaction has been studied. The objectives of the present investigation are to explore the selectivity of vanillin towards chromium(VI), to identify the oxidation products of vanillin and to suggest a suitable oxidation mechanism.

\section{Experimental}

\section{Materials}

All employed chemicals in the present work were Merck-Aldrich reagents and bidistilled water was used in the preparation of their solutions. Vanillin solution was prepared by dissolving the sample in bidistilled water. Required solution of $\mathrm{Cr}(\mathrm{VI})$ was freshly prepared by dissolving the requisite weight of potassium chromate sample in bidistilled water and standardized it spectrophotometrically.

\section{Kinetic measurements}

Kinetic runs were performed under pseudo-first order conditions (vanillin was presented in a large excess relative to $\mathrm{Cr}(\mathrm{VI})$ oxidant). The reaction was followed by monitoring the decay of $\mathrm{Cr}(\mathrm{VI})$ absorbance at $\lambda_{\max }=350 \mathrm{~nm}$, its maximum absorption wavelength. Shimadzu UV-VIS-NIR-3600 double-beam spectrophotometer was used for all absorbance measurements with temperature controlling system.

First order plots were linear up to more than two half-lives of the reaction completion and the pseudo-first order rate constants $\left(\mathrm{k}_{\mathrm{obs}}\right)$ have been calculated by the least-squares method using such plots. The kinetic runs were reproducible to within $\pm 2-3 \%$. The reaction orders with respect to the reactants were calculated as the gradients of double logarithms plots between $\mathrm{k}_{\mathrm{obs}}$ and concentration of vanillin substrate and sulfuric acid at fixed other conditions.

\section{Results}

\section{Spectral changes}

The spectral changes throughout the oxidation of vanillin by $\mathrm{Cr}(\mathrm{VI})$ in sulfuric acid medium are illustrated in Figure 1. The main

${ }^{*}$ Corresponding author: Ahmed Fawzy, Associate Professor, Chemistry Department Faculty of Applied Science, Umm Al-Qura University, 21955 Makkah, Saudi Arabia, Tel: 966-590-994-316; Fax 006-991-255-511-07; E-mail: afsaad13@yahoo.com

Received March 30, 2016; Accepted April 29, 2016; Published May 04, 2016

Citation: Fawzy A, Zaafarany I, Khairou K, Althagafi I, Alfahemi J (2016) Kinetics and Mechanism of Oxidation of Vanillin by Chromium(VI) in Sulfuric Acid Medium. Mod Chem appl 4: 179. doi:10.4172/2329-6798.1000179

Copyright: $\odot 2016$ Fawzy A, et al. This is an open-access article distributed under the terms of the Creative Commons Attribution License, which permits unrestricted use, distribution, and reproduction in any medium, provided the original author and source are credited. 


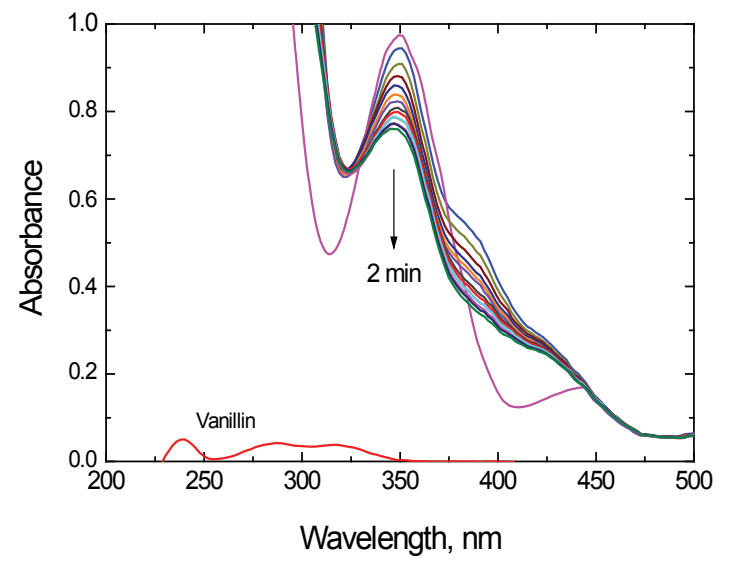

Figure 1: Spectral changes during the oxidation of vanillin by Chromium(VI) in sulfuric acid solution. $[\mathrm{Cr}(\mathrm{VI})]=5.0 \times 10^{-4},[\mathrm{VAN}]=8.0 \times 10^{-3},\left[\mathrm{H}^{+}\right]=1.0$ and $\mathrm{I}=2.0 \mathrm{~mol} \mathrm{dm}^{-3}$ at $25^{\circ} \mathrm{C}$.

characteristic feature in the scanned spectra was the gradual decay of $\mathrm{Cr}(\mathrm{VI})$ band with time at $\lambda=350 \mathrm{~nm}$. Also, there was a change in the shape of spectra with appearance of an absorption band in the region of $370-400 \mathrm{~nm}$.

\section{Reaction stoichiometry}

To determine the reaction stoichiometry, various reaction mixtures containing different ratios of $\mathrm{Cr}(\mathrm{VI})$ to the vanillin substrate were mixed at constant acidity, ionic strength and temperature then were kept for 12 hours in a dark place. The stoichiometry which was determined spectrophotometrically indicated consuming two moles of $\mathrm{Cr}(\mathrm{VI})$ for three mole of vanillin substrate to yield the oxidation products as shown in the following equation,

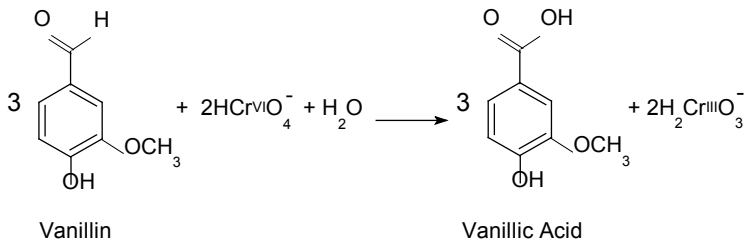

The oxidation product of vanillin was identified as the corresponding carboxylic acid (vanillic acid) by both spectral and chemical analyses as reported $[25,26]$. Similar oxidation product of vanillin has been also reported earlier [2,3].

\section{Dependence of the oxidation rate on [chromium(VI)]}

The effect of chromium(VI) concentration on the rate of reaction was studied by varying its concentration in the range of $(2.0-10.0) \times$ $10^{-4} \mathrm{~mol} \mathrm{dm}^{-3}$ at fixed [VAN], $\left[\mathrm{H}^{+}\right]$and ionic strength. The obtained first order plots were found to be linear for more than two half-lives of the reaction completion. Also, the value of $\mathrm{k}_{\mathrm{obs}}$ was independent of the initial $[\mathrm{Cr}(\mathrm{VI})]$ as listed in Table 1 . The results indicated that the order of reaction with respect to $[\mathrm{Cr}(\mathrm{VI})]$ is confirmed to be one.

\section{Dependence of the oxidation rate on [vanillin]}

The value of $\mathrm{k}_{\mathrm{obs}}$ was measured at various concentrations of the vanillin substrate at constant $[\mathrm{Cr}(\mathrm{VI})],\left[\mathrm{H}^{+}\right]$, ionic strength and temperature. The results showed that increasing vanillin concentration increased the oxidation rate. A plot of $\mathrm{k}_{\mathrm{obs}}$ versus [VAN] was linear with a non-zero intercept (Figure 2) confirming that the reaction order with respect to [VAN] was less than unity.

\section{Dependence of the oxidation rate on [acid]}

The effect of $\left[\mathrm{H}^{+}\right]$on the oxidation rate was examined by carrying out the kinetic runs at various hydrogen ion concentration in the range (0.4$1.9 \mathrm{~mol} \mathrm{dm}^{-3}$ ) while other variables were kept constant. Increasing acid concentration was found to increase the oxidation rate (Table 1). A plot of $\log \mathrm{k}_{\text {obs }}$ versus $\log \left[\mathrm{H}^{+}\right]$was linear with a slope of 0.68 (Figure 3 ) confirming the fractional-first order dependence of the reaction with respect to $\left[\mathrm{H}^{+}\right]$.

\begin{tabular}{|c|c|c|c|c|}
\hline $\begin{array}{l}10^{4}[\mathrm{Cr}(\mathrm{VI})] \\
\left(\mathrm{mol} \mathrm{dm}^{-3}\right)\end{array}$ & $\begin{array}{l}10^{3}[\text { VAN] } \\
\left(\mathrm{mol} \mathrm{dm}^{-3}\right)\end{array}$ & $\begin{array}{c}{\left[\mathrm{H}^{+}\right]} \\
\left(\mathrm{mol} \mathrm{dm} \mathbf{~ d m}^{-3}\right)\end{array}$ & $\begin{array}{c}I \\
\left(\mathrm{~mol} \mathrm{dm}^{-3}\right)\end{array}$ & $\begin{array}{c}10^{5} k_{\text {obs }} \\
\left(\mathrm{s}^{-1}\right)\end{array}$ \\
\hline 2.0 & 8.0 & 1.0 & 2.0 & 14.7 \\
\hline 3.0 & 8.0 & 1.0 & 2.0 & 15.1 \\
\hline 4.0 & 8.0 & 1.0 & 2.0 & 16.0 \\
\hline 5.0 & 8.0 & 1.0 & 2.0 & 15.2 \\
\hline 6.0 & 8.0 & 1.0 & 2.0 & 14.8 \\
\hline 8.0 & 8.0 & 1.0 & 2.0 & 15.6 \\
\hline 10.0 & 8.0 & 1.0 & 2.0 & 14.9 \\
\hline 5.0 & 2.0 & 1.0 & 2.0 & 4.9 \\
\hline 5.0 & 4.0 & 1.0 & 2.0 & 8.8 \\
\hline 5.0 & 6.0 & 1.0 & 2.0 & 12.2 \\
\hline 5.0 & 8.0 & 1.0 & 2.0 & 15.2 \\
\hline 5.0 & 10.0 & 1.0 & 2.0 & 19.0 \\
\hline 5.0 & 12.0 & 1.0 & 2.0 & 20.9 \\
\hline 5.0 & 14.0 & 1.0 & 2.0 & 24.3 \\
\hline 5.0 & 8.0 & 0.4 & 2.0 & 8.1 \\
\hline 5.0 & 8.0 & 0.6 & 2.0 & 11.0 \\
\hline 5.0 & 8.0 & 0.8 & 2.0 & 13.2 \\
\hline 5.0 & 8.0 & 1.0 & 2.0 & 15.2 \\
\hline 5.0 & 8.0 & 1.3 & 2.0 & 18.1 \\
\hline 5.0 & 8.0 & 1.6 & 2.0 & 21.2 \\
\hline 5.0 & 8.0 & 1.9 & 2.0 & 23.6 \\
\hline 5.0 & 8.0 & 1.0 & 2.0 & 15.2 \\
\hline 5.0 & 8.0 & 1.0 & 2.3 & 15.7 \\
\hline 5.0 & 8.0 & 1.0 & 2.6 & 16.4 \\
\hline 5.0 & 8.0 & 1.0 & 3.0 & 15.9 \\
\hline 5.0 & 8.0 & 1.0 & 3.3 & 16.2 \\
\hline 5.0 & 8.0 & 1.0 & 3.6 & 17.1 \\
\hline 5.0 & 8.0 & 1.0 & 4.0 & 16.4 \\
\hline
\end{tabular}

Experimental error $\pm 3 \%$

Table 1: Effect of variation of $[\mathrm{Cr}(\mathrm{VI})],[\mathrm{VAN}],\left[\mathrm{H}^{+}\right]$and ionic strength $(I)$ on the observed first order rate constant $k_{\text {obs }}$ in the oxidation of vanillin by chromium $(\mathrm{VI})$ in sulfuric acid solution at $25^{\circ} \mathrm{C}$.

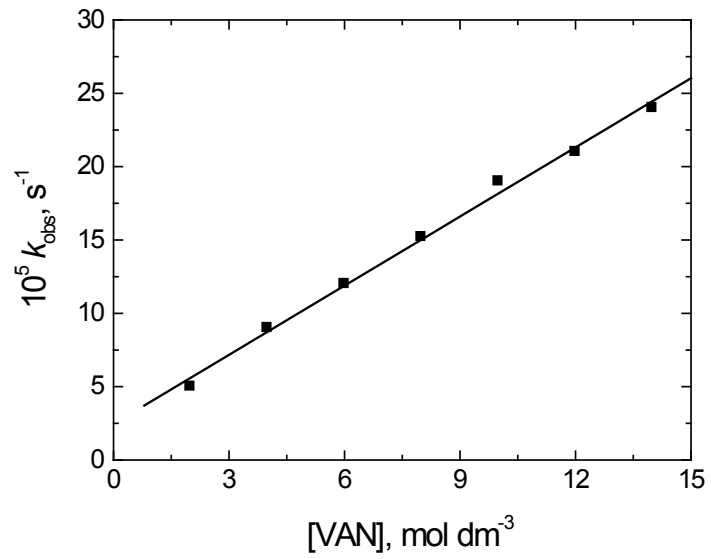

Figure 2: Effect of variation of [VAN] on the observed first order rate constant $k_{\text {obs }}$ in the oxidation of vanillin by Chromium $(\mathrm{VI})$ in sulfuric acid solution. [ $\left.\mathrm{Cr}(\mathrm{VI})\right]$ $=5.0 \times 10^{-4},\left[\mathrm{H}^{+}\right]=1.0$ and $I=2.0 \mathrm{~mol} \mathrm{dm}^{-3}$ at $25^{\circ} \mathrm{C}$. 


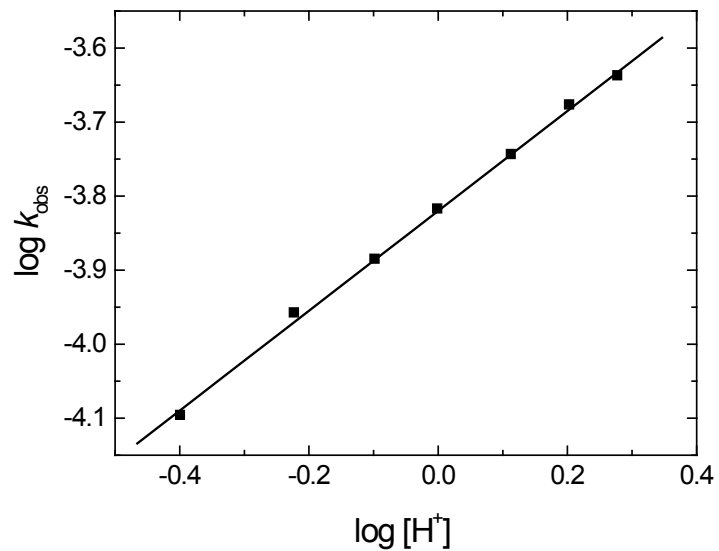

Figure 3: Plot of $\log k_{\text {oss }}$ versus $\log \left[\mathrm{H}^{+}\right]$in the oxidation of vanillin by Chromium(VI) in sulfuric acid solution. $[\mathrm{Cr}(\mathrm{VI})]=5.0 \times 10^{-4}$, [VAN] $=8.0 \times 10^{-3}$ and $I=2.0 \mathrm{~mol} \mathrm{dm}^{-3}$ at $25^{\circ} \mathrm{C}$

\section{Dependence of the oxidation rate on the ionic strength and dielectric constant}

The ionic strength was varied from 2.0 to $4.0 \mathrm{~mol} \mathrm{dm}^{-3} \mathrm{using}$ sodium sulfate at constant $[\mathrm{VAN}],[\mathrm{Cr}(\mathrm{VI})]$ and $\left[\mathrm{H}^{+}\right]$. Increasing the ionic strength had a negligible effect on the reaction rate (Table 1). The effect of the dielectric constant (D) of the reaction medium on the oxidation rate has been investigated at different solvent compositions of acetic acid and water in the reaction medium. As for ionic strength, changing dielectric constant of the medium did not affect the reaction rate.

\section{Dependence of the oxidation rate on [manganese(II)]}

To explore the involvement of chromium(IV) as an intermediate species of chromium in the oxidation reaction, various concentrations of $\mathrm{Mn}$ (II) ion have been added to the reaction medium. The results showed that the oxidation rate decreased with increasing $[\mathrm{Mn}(\mathrm{II})]$ as illustrated in Figure 4.

\section{Dependence of the oxidation rate on temperature}

The oxidation rate was measured at five temperatures, namely, $293,298,303,308$ and $313 \mathrm{~K}$ with varying both [VAN] and $\left[\mathrm{H}^{+}\right]$. The oxidation rate increased with raising temperature. The activation parameters of the rate constant of the rate-determining step $\left(\mathrm{k}_{1}\right)$ and the thermodynamic quantities of the equilibrium constants involved in the oxidation mechanism $\left(\mathrm{K}_{1}\right.$ and $\left.\mathrm{K}_{2}\right)$ were calculated and listed in Tables 2 and 3.

\section{Polymerization test for free radical intermediate}

Intervention of free radicals during the oxidation reaction was examined by the polymerization test where a known quantity of acrylonitrile was added to the partially oxidized reaction mixture and kept for about $4 \mathrm{~h}$ in an inert atmosphere. On diluting the reaction mixture with methanol, no white precipitate was formed thus confirming the absence of free radical in the oxidation reaction.

\section{Discussion}

It has been reported [27] that, in redox reactions including $\mathrm{Cr}(\mathrm{VI})$ oxidant in acid media, there are two suggested reaction mechanisms for electron transfer, the first one was proposed to involve a successive one-electron transfer in two steps. The second suggested one was a simultaneous two-electron transfer in a single step. Both mechanisms may be considered during reduction of $\mathrm{Cr}(\mathrm{VI})$ to form either $\mathrm{Cr}(\mathrm{V})$ or
$\mathrm{Cr}(\mathrm{IV})$ species, respectively [28-30]. In the present investigation, the negative result of free radical intervention excluded formation of $\mathrm{Cr}(\mathrm{V})$ species. On the other hand, the involvement of $\mathrm{Cr}(\mathrm{IV})$ species in the reaction can be proved by decreasing the oxidation rate upon addition of manganese(II) to the reaction medium. This is because $\mathrm{Mn}$ (II) has been recognized as a frequently tool for trapping $\mathrm{Cr}(\mathrm{IV})$ intermediate species [31]. Therefore, if $\mathrm{Cr}(\mathrm{IV})$ species was involved, addition of $\mathrm{Mn}$ (II) to the reaction will remove it from the reaction resulting in a decrease in the oxidation rate according to the equation, $\mathrm{Cr}(\mathrm{IV})+$ $\mathrm{Mn}(\mathrm{II})=\mathrm{Cr}(\mathrm{III})+\mathrm{Mn}(\mathrm{III})$. The observed decrease in the oxidation rate upon addition of $\mathrm{Mn}$ (II) (Figure 4) is considered as a good evidence to the contribution of $\mathrm{Cr}(\mathrm{IV})$. The inhibition effect occurs due to the competition existing between the substrate and $\mathrm{Mn}$ (II) to react with Cr(IV).

On the other hand, chromium(VI) was suggested $[32,33]$ to exist in aqueous acid media mainly as acid chromate, $\mathrm{H}_{2} \mathrm{CrO}_{4}$, as represented by the first step in Scheme 1. Increasing the oxidation rate upon increasing $\left[\mathrm{H}^{+}\right]$suggested the protolytic process of the chromate ion, i.e., the protonated species of the chromate oxidant $\left(\mathrm{H}_{2} \mathrm{CrO}_{4}\right)$ may be considered as the kinetically reactive species which play the main role in the oxidation kinetics.

\begin{tabular}{|c|c|c|c|c|c|c|c|c|c|}
\hline \multirow[b]{2}{*}{$\begin{array}{c}\text { Rate } \\
\text { Constant } \\
\left(\mathbf{s}^{-1}\right)\end{array}$} & \multicolumn{5}{|c|}{ Temperature (K) } & \multicolumn{4}{|c|}{ Activation parameters } \\
\hline & 288 & 293 & 298 & 303 & 308 & $\begin{array}{c}\Delta \boldsymbol{S}^{\neq} \\
\left(\mathrm{Jmol}^{-}\right. \\
\left.{ }^{1} \mathrm{~K}^{-1}\right)\end{array}$ & $\begin{array}{c}\Delta \boldsymbol{H}^{\ddagger} \\
(\mathbf{k J} \\
\left.\mathrm{mol}^{-1}\right)\end{array}$ & $\begin{array}{c}\Delta \boldsymbol{G}^{\neq} \\
(\mathbf{k J} \\
\left.\mathrm{mol}^{-1}\right)\end{array}$ & $\begin{array}{c}E_{\mathrm{a}}^{\neq} \\
\left(\mathrm{kJ}^{-1}\right. \\
\left.\mathrm{mol}^{-1}\right)\end{array}$ \\
\hline $10^{4} k_{1}$ & 4.61 & 5.82 & 7.50 & 9.82 & 12.19 & -106.71 & 33.98 & 65.78 & 35.57 \\
\hline
\end{tabular}

Experimental error $\pm 4 \%$

Table 2: Values of the rate constant of the slow step $\left(k_{1}\right)$ at different temperatures and its associated activation parameters in the oxidation of vanillin by Chromium( $(\mathrm{VI})$ in sulfuric acid solution.

\begin{tabular}{|c|c|c|c|c|c|c|c|c|}
\hline \multirow{2}{*}{$\begin{array}{c}\text { Equilibrium } \\
\text { constant } \\
\left(\mathbf{d m}^{3} \mathrm{~mol}^{-1}\right)\end{array}$} & \multicolumn{5}{|c|}{ Temperature (K) } & \multicolumn{3}{|c|}{ Thermodynamic parameters } \\
\hline & 293 & 298 & 303 & 08 & 313 & $\begin{array}{c}\Delta H^{\circ} \\
\left(\mathrm{kJ} \mathrm{mol}^{-1}\right)\end{array}$ & $\begin{array}{c}\Delta \mathbf{G}^{\circ}{ }_{298} \\
\left(\mathrm{~kJ} \mathrm{~mol}^{-1}\right)\end{array}$ & $\begin{array}{c}\Delta S^{\circ} \\
\left(\mathrm{Jmol}^{-1} \mathbf{K}^{-1}\right)\end{array}$ \\
\hline $10^{2} K_{1}$ & & & & & & & & \\
\hline $10^{-2} K_{2}$ & 53 & 5.46 & 4.73 & 3.35 & 2.84 & -33.42 & -15.61 & -59.77 \\
\hline
\end{tabular}

Experimental error $\pm 3 \%$

Table 3: Values of the equilibrium constants $\left(K_{1}\right.$ and $\left.K_{2}\right)$ at different temperatures and their thermodynamic quantities in the oxidation of vanillin by Chromium(VI) in sulfuric acid solution.

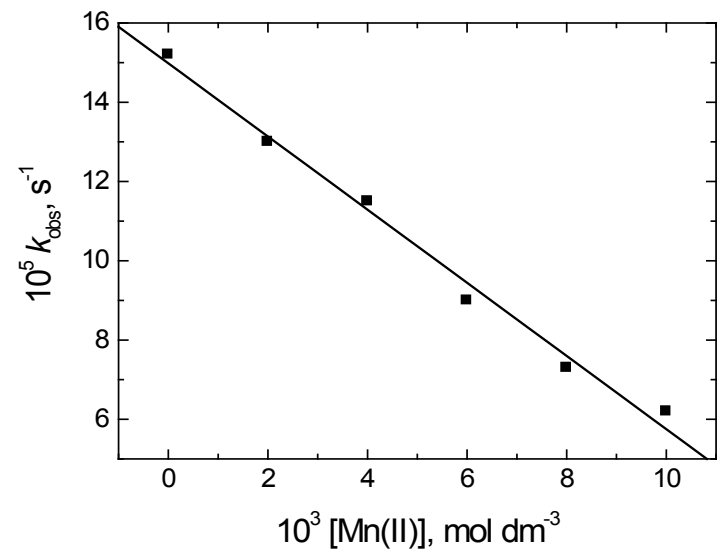

Figure 4: Effect of Manganese(II) on the observed first order rate constant $k$ in the oxidation of vanillin by chromium $(\mathrm{VI})$ in sulfuric acid solution. $[\mathrm{Cr}(\mathrm{VI})]=$ $5.0 \times 10^{-4},[\mathrm{VAN}]=8.0 \times 10^{-3},\left[\mathrm{H}^{+}\right]=1.0$ and $I=2.0 \mathrm{~mol} \mathrm{dm}^{-3}$ at $25^{\circ} \mathrm{C}$. 


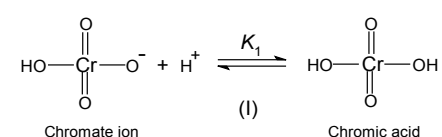<smiles>[Y]c1ccc(O)c(OC)c1</smiles>

$$
\text { Vanillin }
$$$$
\mathrm{HO}
$$<smiles>COc1cc(C(=O)O)ccc1O</smiles><smiles>COc1cc(C=O)ccc1O</smiles>

Vanillin acid<smiles>COc1cc(C=O)ccc1O</smiles><smiles>COc1cc(C=O)ccc1O</smiles>

Scheme 1: Mechanistic scheme of the oxidation of vanillin by Chromium(VI) in sulfuric acid solution.

The present reaction between chromium(VI) and vanillin in $\mathrm{H}_{2} \mathrm{SO}_{4}$ solution showed a stoichiometry of 3:2 (VAN : $\mathrm{Cr}(\mathrm{VI})$ ) with a first order dependence with respect to $[\mathrm{Cr}(\mathrm{VI})]$ and a less than unit order dependence with respect to [VAN]. The less than unit order dependence on vanillin concentration can be attributed to complex formation between vanillin and chromium(VI) in a pre-equilibrium step. The formation of the complex was also proved kinetically [34] by a non-zero intercept of the plot of $1 / \mathrm{k}_{\mathrm{obs}}$ versus $1 /$ [VAN] as shown in Figure 5. Further evidence for complex formation was obtained from the UV-Vis spectra as shown in Figure 1. The complex formation between chromium(VI) and different organic compounds in acid media was also reported [16-19,35,36]. Furthermore, the negligible effects of both ionic strength and dielectric constant of the medium were consistent with a reaction occurs between two neutral molecules [37-39] i.e., between vanillin and $\mathrm{H}_{2} \mathrm{CrO}_{4}$.

Based on the forgoing aspects, the most reasonable reaction mechanism which may be suggested (Scheme 1), involves a fast complexation between the vanillin substrate and the kinetically active chromium(VI) species $\left(\mathrm{H}_{2} \mathrm{CrO}_{4}\right)$, step (II), to give an intermediate complex $(\mathrm{C})$. The latter was slowly decomposed in the rate-determining step followed by subsequent fast steps, (III) - (V), to give rise to the final oxidation products.

The suggested mechanistic Scheme 1 leads to the following rate law expression (Appendix A),

$$
\text { Rate }=\frac{k_{1} K_{1} K_{2}\left[\mathrm{HCrO}_{4}^{-}\right][\mathrm{VAN}]\left[\mathrm{H}^{+}\right]}{1+K_{1}\left[\mathrm{H}^{+}\right]+K_{1} K_{2}[\mathrm{VAN}]\left[\mathrm{H}^{+}\right]}
$$

Under pseudo-first order condition,

$$
\text { Rate }=\frac{-d\left[\mathrm{HCrO}_{4}^{-}\right]}{d t}=k_{\mathrm{obs}}\left[\mathrm{HCrO}_{4}^{-}\right]
$$

Comparison of Eq. (1) and (2) gives,

$$
k_{\mathrm{obs}}=\frac{k_{1} K_{1} K_{2}[\mathrm{VAN}]\left[\mathrm{H}^{+}\right]}{1+K_{1}\left[\mathrm{H}^{+}\right]+K_{1} K_{2}[\mathrm{VAN}]\left[\mathrm{H}^{+}\right]}
$$

and with rearrangement of Eq. (3) leads to the following equations,

$$
\begin{aligned}
& \frac{1}{k_{\mathrm{obs}}}=\left(\frac{1+K_{1}\left[\mathrm{H}^{+}\right]}{k_{1} K_{1} K_{2}\left[\mathrm{H}^{+}\right]}\right) \frac{1}{[\mathrm{VAN}]}+\frac{1}{k_{1}} \\
& \frac{1}{k_{\mathrm{obs}}}=\left(\frac{1}{k_{1} K_{1} K_{2}[\mathrm{VAN}]}\right) \frac{1}{\left[\mathrm{H}^{+}\right]}+\left(\frac{1}{k_{1} K_{2}[\mathrm{VAN}]}+\frac{1}{k_{1}}\right)
\end{aligned}
$$

According to Eq. (4) and (5), the plots of $1 / \mathrm{k}_{\mathrm{obs}}$ versus $1 /[\mathrm{VAN}]$ at constant $\left[\mathrm{H}^{+}\right]$and $1 / \mathrm{k}_{\mathrm{obs}}$ versus $1 /\left[\mathrm{H}^{+}\right]$at constant [VAN] should give straight lines with positive intercepts on the $1 / \mathrm{k}_{\mathrm{obs}}$ axes, as were experimentally observed (Figures 5 and 6 respectively). Values of the rate constant of the slow step $\left(\mathrm{k}_{1}\right)$ along with the equilibrium constants $\mathrm{K}_{1}$ and $\mathrm{K}_{2}$ at different temperatures were calculated from the slopes and

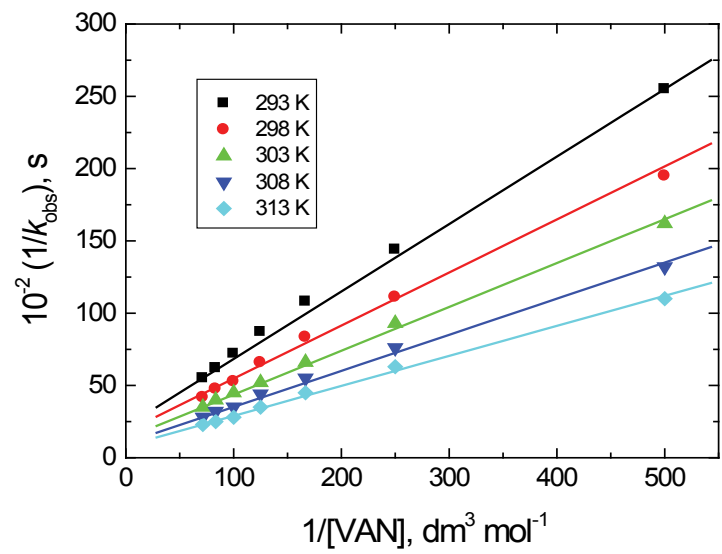

Figure 5: Plots of $1 / k_{\text {s }}$ versus $1 /[\mathrm{VAN}]$ at different temperatures in the oxidation of vanillin by Chromium( $(\mathrm{VI})$ in sulfuric acid solution. $[\mathrm{Cr}(\mathrm{VI})]=5.0 \times$ $10^{-4},\left[\mathrm{H}^{+}\right]=1.0$ and $\mathrm{I}=2.0 \mathrm{~mol} \mathrm{dm}^{-3}$

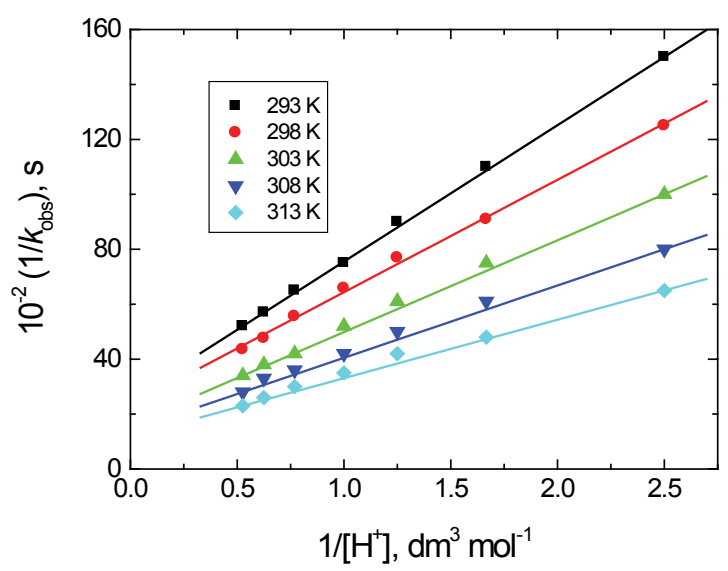

Figure 6: Plots of $1 / k$ versus $1 /\left[\mathrm{H}^{+}\right]$at different temperatures in the oxidation of vanillin by Chromium $(\mathrm{VI})$ in sulfuric acid solutions. $[\mathrm{Cr}(\mathrm{VI})]=5.0 \times 10^{-4}$, [VAN] $=8.0 \times 10^{-3}$ and $I=2.0 \mathrm{~mol} \mathrm{dm}^{-3}$. 
intercepts of such plots and were listed in Tables 2 and 3, respectively. The obtained values of the protonation constant of mono hydrogen chromate $\left(\mathrm{K}_{1}\right)$ are in agreement with those reported in the literature $[40,41]$.

The activation parameters of the rate constants of the ratedetermining step $\left(\mathrm{k}_{1}\right)$ are calculated using Arrhenius and Eyring plots, and were listed in Table 2. Also, the thermodynamic quantities of the equilibrium constants were determined using van't Hoff plots and were listed in Table 3.

The obtained large negative values of $\Delta \mathrm{S}^{\neq}$are consistent with the formation of compacted intermediate complex of inner-sphere nature $[42,43]$. The experimental values of $\Delta \mathrm{H}^{\neq}$and $\Delta \mathrm{S}^{\neq}$were both favorable for electron-transfer process [44]. Again, the positive values of $\Delta \mathrm{H}^{\ddagger}$ and $\Delta \mathrm{G}^{\neq}$indicate endothermic formation of the intermediate and its nonspontaneity, respectively.

\section{Conclusions}

The kinetics of oxidation of vanillin by chromium(VI) has been investigated in sulfuric acid solutions. $\mathrm{H}_{2} \mathrm{CrO}_{4}$ is suggested to be the kinetically active species of the oxidant which takes part in the oxidation reaction. The final oxidation product of vanillin was identified as vanillic acid. The rate and equilibrium constants involved in the different steps of the proposed mechanism along with their activation and thermodynamic parameters were evaluated and discussed.

\section{Appendix A}

\section{Derivation of the rate law expression:}

According to the suggested mechanistic Scheme 1,

$$
\begin{aligned}
& K_{1}=\frac{\left[\mathrm{H}_{2} \mathrm{CrO}_{4}\right]}{\left[\mathrm{HCrO}_{4}^{-}\right]\left[\mathrm{H}^{+}\right]},\left[\mathrm{H}_{2} \mathrm{CrO}_{4}\right]=\mathrm{K}_{1}\left[\mathrm{HCrO}_{4}^{-}\right]\left[\mathrm{H}^{+}\right] \\
& \text {and } K_{2}=\frac{[\mathrm{C}]}{[\mathrm{VAN}]\left[\mathrm{H}_{2} \mathrm{CrO}_{4}\right]}, \\
& {[\mathrm{C}]=\mathrm{K}_{2}[\mathrm{VAN}]\left[\mathrm{H}_{2} \mathrm{CrO}_{4}\right]=\mathrm{K}_{1} \mathrm{~K}_{2}[\mathrm{VAN}]\left[\mathrm{HCrO}_{4}^{-}\right]\left[\mathrm{H}^{+}\right]}
\end{aligned}
$$

From step (III) in Scheme 1, the rate law expression can be expressed by Eq. (A.3),

$$
\text { Rate }=\frac{-d\left[\mathrm{HCrO}_{4}^{-}\right]}{d t}=k_{1}[\mathrm{C}]
$$

Substituting Eq. (A.2) into Eq. (A.3) leads to,

$$
\text { Rate }=\mathrm{k}_{1} \mathrm{~K}_{1} \mathrm{~K}_{2}[\mathrm{VAN}]\left[\mathrm{HCrO}_{4}^{-}\right]\left[\mathrm{H}^{+}\right]
$$

The total concentration of $\mathrm{HCrO}_{4}$ is given by,

$$
\left[\mathrm{HCrO}_{4}^{-}\right]_{\mathrm{T}}=\left[\mathrm{HCrO}_{4}^{-}\right]_{\mathrm{F}}+\left[\mathrm{H}_{2} \mathrm{CrO}_{4}\right]+[\mathrm{C}]
$$

Where ' $\mathrm{T}$ ' and ' $\mathrm{F}$ ' stand for total and free.

Substituting Eq. (A.1) into Eq. (A.5) gives, $\left[\mathrm{H}^{+}\right]$

$\left[\mathrm{HCrO}_{4}^{-}\right]_{\mathrm{T}}=\left[\mathrm{HCrO}_{4}^{-}\right]_{\mathrm{F}}+\mathrm{K}_{1}\left[\mathrm{HCrO}_{4}^{-}\right]\left[\mathrm{H}^{+}\right]+\mathrm{K}_{1} \mathrm{~K}_{2}[\mathrm{VAN}]\left[\mathrm{HCrO}_{4}^{-}\right]$

$$
\left[\mathrm{HCrO}_{4}^{-}\right]_{\mathrm{T}}=\left[\mathrm{HCrO}_{4}^{-}\right]_{\mathrm{F}}\left(1+\mathrm{K}_{1}\left[\mathrm{H}^{+}\right]+\mathrm{K}_{1} \mathrm{~K}_{2}[\mathrm{VAN}]\left[\mathrm{H}^{+}\right]\right)
$$

Therefore,

$$
\left[\mathrm{HCrO}_{4}{ }^{-}\right]_{\mathrm{F}}=\frac{\left[\mathrm{HCrO}_{4}{ }^{-}\right]_{\mathrm{T}}}{1+K_{1}\left[\mathrm{H}^{+}\right]+K_{1} K_{2}[\mathrm{VAN}]\left[\mathrm{H}^{+}\right]}
$$

Also, the total concentration of vanillin is given by,

$[\mathrm{VAN}]_{\mathrm{T}}=[\mathrm{VAN}]_{\mathrm{F}}+[\mathrm{C}]=[\mathrm{VAN}]_{\mathrm{F}}+\mathrm{K}_{1} \mathrm{~K}_{2}[\mathrm{VAN}]\left[\mathrm{HCrO}_{4}^{-}\right]\left[\mathrm{H}^{+}\right]$
Therefore,

$$
[\mathrm{VAN}]_{\mathrm{F}}=\frac{[\mathrm{VAN}]_{\mathrm{T}}}{1+K_{1} K_{2}\left[\mathrm{HCrO}_{4}^{-}\right]\left[\mathrm{H}^{+}\right]}
$$

Because of low concentration of $\mathrm{HCrO}_{4}^{-}$used, the term $\mathrm{K}_{1} \mathrm{~K}_{2}\left[\mathrm{HCrO}_{4}^{-}\right]\left[\mathrm{H}^{+}\right]$in the denominator can be neglected. Hence,

$[\mathrm{VAN}]_{\mathrm{F}}=[\mathrm{VAN}]_{\mathrm{T}}$

In view of the high concentrations of $\left[\mathrm{H}^{+}\right]$we can write,

$\left[\mathrm{H}^{+}\right]_{\mathrm{F}}=\left[\mathrm{H}^{+}\right]_{\mathrm{T}}$

Substituting Eq. (A.8), (A.11) and (A.12) into Eq. (A.4) (and omitting ' $T$ ' and ' $F$ ' subscripts) gives,

$$
\text { Rate }=\frac{k_{1} K_{1} K_{2}\left[\mathrm{HCrO}_{4}{ }^{-}\right][\mathrm{VAN}]\left[\mathrm{H}^{+}\right]}{1+K_{1}\left[\mathrm{H}^{+}\right]+K_{1} K_{2}[\mathrm{VAN}]\left[\mathrm{H}^{+}\right]}
$$

Under pseudo-first order condition,

$$
\text { Rate }=\frac{-d\left[\mathrm{HCrO}_{4}^{-}\right]}{d t}=k_{o b s}\left[\mathrm{HCrO}_{4}{ }^{-}\right]
$$

Comparing Eqs. (A.13) and (A.14), the following relationship is obtained,

$$
k_{\mathrm{obs}}=\frac{k_{1} K_{1} K_{2}[\mathrm{VAN}]\left[\mathrm{H}^{+}\right]}{1+K_{1}\left[\mathrm{H}^{+}\right]+K_{1} K_{2}[\mathrm{VAN}]\left[\mathrm{H}^{+}\right]}
$$

and with rearrangement, the following equations are obtained,

$$
\begin{aligned}
& \frac{1}{k_{\mathrm{obs}}}=\left(\frac{1+K_{1}\left[\mathrm{H}^{+}\right]}{k_{1} K_{1} K_{2}\left[\mathrm{H}^{+}\right]}\right) \frac{1}{[\mathrm{VAN}]}+\frac{1}{k_{1}} \\
& \frac{1}{k_{\mathrm{obs}}}=\left(\frac{1}{k_{1} K_{1} K_{2}[\mathrm{VAN}]}\right) \frac{1}{\left[\mathrm{H}^{+}\right]}+\frac{1}{k_{1} K_{2}[\mathrm{VAN}]}+\frac{1}{k_{1}}
\end{aligned}
$$

\section{References}

1. Liu Y, Liu H, Li N (2008) Comparative study of the electro-catalytic oxidation and mechanism of nitrophenols at Bi-doped lead dioxide. Appl Catal B 84: 297302

2. Jose TP, Nandibewoor ST, Tuwar SM (2006) Kinetics and mechanism of oxidation of vanillin by hexacyanoferrate(III) in aqueous alkaline medium. J Solution Chem 35: 51-62.

3. Munavalli DS, Chimatadar SA, Nandibewoor ST (2007) Oxidation of vanillin by a new oxidant diperiodatoargentate(III) in aqueous alkaline medium. Ind Eng Chem Res 46: 1459-1464.

4. Mishra $P(2009)$ Kinetics and mechanisms of oxidation of 4-hydroxy-3-methoxy benzaldehyde (vanillin) by $\mathrm{Bi}(\mathrm{V})$ in aqueous alkaline medium. Int $\mathrm{J}$ Pharmtech Res 1: 1234-1240.

5. Kathari C, Pol P, Nandibewoor ST (2002) The kinetics and mechanism of oxidation of vanillin by diperiodatonickelate(IV) in aqueous alkaline medium Turk J Chem 26: 229-236.

6. Patil DG, Magdum PA, Nandibewoor ST (2015) Mechanistic Investigations of uncatalyzed and ruthenium(III) catalyzed oxidation of vanillin by periodate in aqueous alkaline medium. J Solution Chem 44: 1205-1223.

7. Satapathy PK, Baral DK, Aswar AS, Mohanty P (2013) Kinetics and mechanism of oxidation of vanillin by cerium(IV) in aqueous perchlorate medium. Indian Chem Tech 20: 271-275

8. Katz SA, Salem H (1993) The toxicology of chromium with respect to its chemical speciation: a review. J Appl Toxicol 13: 217-224.

9. Kostecki PT (1998) Chromium in soil: perspectives in chemistry, health, and environmental regulation. J Soil Contamin 6: 561-568.

10. Costa M (1997) Toxicity and carcinogenicity of $\mathrm{Cr}(\mathrm{VI})$ in animal models and humans. Crit Rev Toxicol 27: 431-442.

11. Chimatadar SA, Koujalagi SB, Nandibewoor ST (2001) Kinetics and mechanism of palladium(II) catalyzed chromium(VI) oxidation of mercury $(\mathrm{I})$ in aqueous sulphuric acid. Transition Met Chem 26: 662-667. 
Citation: Fawzy A, Zaafarany I, Khairou K, Althagafi I, Alfahemi J (2016) Kinetics and Mechanism of Oxidation of Vanillin by Chromium(VI) in Sulfuric Acid Medium. Mod Chem appl 4: 179. doi:10.4172/2329-6798.1000179

Page 6 of 6

12. Chimatadar SA, Basavaraj T, Nandibewoor ST (2006) Mechanistic study of quinoliniumdichromate (QDC) oxidation of mercury $(\mathrm{I})$ in aqueous sulfuric acid in the presence of micro amounts of palladium(II). Autocatalysis in catalysis. Polyhedron 25: 2976-2984

13. Sen Gupta KK, Chakladar JK (1974) Kinetics of the chromic acid oxidation of arsenic(III). J Chem Soc Dalton Trans 2: 222-225.

14. Sen Gupta KK, Chakladar JK, Chatterjee AK, Chakladar JK (1973) Kinetics of the oxidation of hypophosphorous and phosphorous acids by chromium(VI). Journal of Inorganic and Nuclear Chemistry 35: 901-908.

15. Espenson JH (1970) Oxidation of transition metal complexes by chromium(VI). Acc Chem Res 3: 347-351.

16. Fawzy A, Ashour SS, Musleh MA, Hassan RM, Asghar BH (2014) Kinetics and mechanistic approach to the chromic acid oxidation of L-tryptophan with a spectral detection of chromium(III) product. J Saudi Chem Soc (In press).

17. Fawzy A, Althagafi I, Tirkistani F, Shaaban M, Morad M (2016) Chromic acid oxidation of methylaminopyrazole formamidine in sulfuric acid medium: A kinetic and mechanistic approach. Am J Phys Chem 5: 1-9.

18. Yarkandi N, Althagafi I, Al-Bonayan A, Fawzy A, Hassan RM (2016) Kinetics and mechanistic aspects of oxidation of iota- and lambda-carrageenans by chromium(VI) in aqueous perchlorate solutions. Chem Sci Rev Lett (In press).

19. Fawzy A, Altass HM (2016) Ruthenium(III)-catalyzed oxidation of alginate and pectate biopolymers by chromic acid in aqueous perchlorate solutions: a comparative kinetic study. Transition Met Chem 41: 115-124.

20. Hasan F, Rocek J (1975) Three-electron oxidations. IX. Chromic acid oxidation of glycolic acid. J Am Chem Soc 97: 1444-1450.

21. Khan Z, Id-Din K (2001) Effect of manganese(II) ions on the oxidation of malic and oxaloethanoic acids by aqueous HCrO-4. Transition Met. Chem 26: 672-678.

22. Manhas MS, Kumar P, Mohamed F, Khan Z (2008) Oxidative degradation of non-ionic surfactant (Triton $X-100)$ by chromium(VI). Colloids Surf $A$ Physicochem Eng Asp 320: 240-246.

23. Odebunmi EO, Obike Al, Owalude SO (2009) Kinetics and mechanism of oxidation of $\mathrm{D}$-xylose and $\mathrm{L}$-arabinose by chromium $(\mathrm{VI})$ ions in perchloric acid medium. Int J Biolog Chem Sci 3: 178-185

24. Bayen R, Das AK (2009) Kinetics and mechanism of oxidation of D-galactose by chromium $(\mathrm{VI})$ in presence of $2,2^{\prime}$-bipyridine catalyst in aqueous micellar media. Open Catal J 2: 71-78.

25. Vogel Al, Furniss BS, Smith PW (1978) Vogel's Textbook of Practical Organic Chemistry. $3^{\text {rd }}$ edition. ELBS, Longman Scientific \& Technical, p: 332.

26. Feigl F (1957) Spot Tests in Organic Analysis. Elsevier, New York, NY, USA.

27. Espenson JH, King EL (1963) Kinetics and mechanism of reaction of chromium(IV) and iron(III) species in acidic solution. J Am Chem Soc 85: 3328-3333.
28. Espenson $\mathrm{JH}$, Wang RT (1972) Oxidation of uranium(IV) by chromium(VI) and the induced oxidation of iodide ions. Inorg Chem 11: 955-959.

29. Sen Gupta KK, Sarkar T (1975) Kinetics of the chromic acid oxidation of glyoxylic and pyruvic acids. Tetrahedron 31: 123-129.

30. Bose RN, Moghaddas S, Gelerinter E (1992) Long-lived chromium(IV) and chromium(V) metabolites in the chromium(VI)-glutathione reaction: NMR, ESR HPLC, and kinetic characterization. Inorg Chem 31: 1987-1994.

31. Milazzo, G, Caroli S, Sharma VK (1978) Tables of Standard Electrode Metal Potentials. Wiley \& Sons, New York, USA.

32. Bailey N, Carrington A, Lott KAK, Symons MCR (1960) Structure and reactivity of the oxyanions of transition metals. Part VIII. Acidities and spectra of protonated oxyanions. J Chem Soc 290-297

33. Sasaki Y (1962) Equilibrium studies on polyanions. 9. The first steps of acidification of chromate Ion in $3 \mathrm{M} \mathrm{Na}(\mathrm{ClO} 4)$ Medium at $25^{\circ} \mathrm{C}$. Acta Chem Scand 16: 719-734.

34. Michaelis L, Menten ML (1913) The kinetics of invertase action. Biochem Z 49: 333-369.

35. Naik PK, Chimatadar SA, Nandibewoor ST (2008) A kinetic and mechanistic study of the oxidation of tyrosine by chromium( $\mathrm{VI})$ in aqueous perchloric acid medium. Transition Met Chem 33: 405-410.

36. Day MC, Selbin JJ (1964) Theoretical inorganic chemistry. Reinhold Publishing Corporation, New York, USA.

37. Frost AA, Person RG (1971) Kinetics and Mechanism. In: Progress in Reaction Kinetics. Rochester $\mathrm{CH}$, Pergamon Press, Oxford.

38. Laidler K (1965) Chemical Kinetics, McGraw-Hill, New York, USA.

39. Amis ES (1966) Solvent effects on reaction rates and mechanisms. Academic Press, New York, USA

40. Freeman WH (2010) Dissociation Constants. In: Modern Inorganic Chemistry (1983), edited by Liptrot GF, Liptrot GP, Haszeldine RN. Unwin Hyman, pp: $22-25$.

41. IUPAC SC-Database (2001) A comprehensive database of published data on equilibrium constants of metal complexes and ligands. Inorganic Chemistry, Higher Education Press, Beijing, China.

42. Hicks KW, Toppen DL, Linck RG (1972) Inner-sphere electron-transfe reactions of vanadium(II) with azidoamine complexes of cobalt(III). Inorg Chem 11: 310-315.

43. Weissbekger A (1974) Investigation of Rates and Mechanism of Reactions. In Techniques of Chemistry, John Wiley \& Sons, p: 421

44. Rangappa KS, Raghavendra MP, Mahadevappa DS, Channegowda D (1998) Sodium N-Chlorobenzenesulfonamide as a Selective Oxidant for Hexosamines in Alkaline Medium: A Kinetic and Mechanistic Study. J Org Chem 63: 531-536. 